\title{
Multiresidue determination and predicted risk assessment of contaminants of emerging concern in marine sediments from the vicinities of submarine sewage outfalls
}

\author{
Dayana M. dos Santos ${ }^{\mathrm{a}, \mathrm{b}, *}$, Lucas Buruaem ${ }^{\mathrm{c}}$, Renato M. Gonçalves ${ }^{\mathrm{a}}$, Mike Williams ${ }^{\mathrm{d}}$, \\ Denis M.S. Abessa ${ }^{\mathrm{c}}$, Rai Kookana ${ }^{\mathrm{d}}$, Mary Rosa R. de Marchi ${ }^{\mathrm{a}}$ \\ a Institute of Chemistry, Univ. Estadual Paulista- UNESP, Araraquara, São Paulo, Brazil \\ ${ }^{\mathrm{b}}$ Chemistry Department, State University of Londrina-UEL, Londrina, Paraná, Brazil \\ ${ }^{\mathrm{c}}$ Biosciences Institute, Univ. Estadual Paulista- UNESP, São Vicente, São Paulo, Brazil \\ ${ }^{\mathrm{d}}$ CSIRO Land and Water, Urrbrae, South Australia, Australia
}

\section{A R T I C L E I N F O}

\section{Keywords:}

Sediment

Emerging contaminants

Risk assessment

\begin{abstract}
A B S T R A C T
Submarine sewage outfalls (SSOs) are considered the main input source of contaminants of emerging concern continuously released in coastal areas, with the potential to cause adverse effects for aquatic organisms. This work presents the investigation of nine endocrine disrupting chemicals (EDCs) and 26 pharmaceutically active chemicals (PhACs) in marine sediments within the vicinities of 7 SSOs along the São Paulo State Coast (Brazil). Method optimization for the multi-residue determination by GC-MS/MS and LC-MS/MS using QuEChERS extraction/clean-up are discussed. Results demonstrate the occurrence of EDCs in concentrations ranging from less than method quantification limits (MQL) to $72.5 \mathrm{ng} \mathrm{g}^{-1}$ in sediments. All PhACs were $<$ MQLs. Nonylphenol was the most ubiquitous compound and the diversity of EDCs increased with an increase in populations serviced by SSOs. The predicted environmental risk assessment considering measured environmental concentrations and ecotoxicity endpoints from literature suggest a high-risk potential in some of the investigated SSOs.
\end{abstract}

\section{Introduction}

The continuous release of unregulated contaminants of emerging concern (CECs) into aquatic environments has the potential to cause adverse effects on exposed aquatic organisms, even at low environmental concentrations. CECs includes contaminants such as endocrine disrupting chemicals (EDCs), a class of synthetic and endogenous chemicals known as mimic natural hormones, with the potential to modulate normal endocrine system functions, such as growth, energy homeostasis and metabolic pathways, differentiation of tissues and organs, and sexual features (Jugan et al., 2010; Sosa-Ferreira et al., 2013). In the case of sex hormones regulation, EDCs can induce the development of female characteristics in aquatic organisms leading to sexual ratio disturbances or sterility, which can affect the population structure (WHO. World Health Organization, 2012). A number of commonly assessed EDCs include endogenous (17 $\beta$-estradiol, estrone and estriol) and synthetic (17 $\alpha$-ethinylestradiol) steroid hormones, alkylphenols (nonylphenol and octylphenol), clorophenols (triclosan and methyltriclosan) and bisphenol A, commonly present in industrial, agricultural and urban effluents. Another class of CECs are the pharmaceutically active chemicals (PhACs), a group of biologically active substances with a broad range of physicochemical properties and used as therapeutic agents in human and veterinary medicine (Bayen et al., 2013; Halm-Lemeille and Gomez, 2016). PhACs are commonly detected in the aquatic environment, which can be related with their widespread use and/or their resistance to wastewater treatments (Coogan et al., 2007; Petrie et al., 2015).

PhACs and EDCs have been detected ubiquitously in all environmental matrices including freshwater, seawater, drinking water, wastewater (Chau et al., 2008; Cerqueira et al., 2008; Gunatilake et al., 2014; Celano et al., 2014), sewage sludge (Cerqueira et al., 2014; Langdon et al., 2011), sediments (Pojana et al., 2007; Berlioz-Barbier et al., 2014), and biota (Gonzalo-Lumbreras et al., 2014). Due to the broad range of physicochemical properties of chemicals classified as PhACs and EDCs they can exhibit variable affinity to solids, although these contaminants are usually investigated within the water column. However, in a constant input scenario coupled with deposition of suspended particulate matter, sediments can become more significant (David et al., 2009; Fernandes et al., 2011). This process can mean sediments are a potential secondary source of contaminants for the

\footnotetext{
* Corresponding author at: Chemistry Department, State University of Londrina (UEL), University Campus, CEP: 86051-990 Londrina, PR, Brazil.

E-mail address: dayana.moscardi@gmail.com (D.M. dos Santos).
} 
system, especially where resuspension of the bed sediments occurs (Sosa-Ferreira et al., 2013). In coastal areas CECs can be mainly detected close to submarine outfalls as well as in industrial and illegal sewage discharges on estuarine/marine interface (Cantwell et al., 2010). In comparison with freshwater ecosystems, few studies have been conducted regarding marine environments, once the expected concentrations of CECs are likely to be reduced due to dilution capacity and action and hydrodynamic processes (Arpin-Pont et al., 2016).

In many cities along the Brazilian Coast the discharge of domestic effluents via submarine sewage outfalls (SSOs) is the main solution for sewage discharge due to its relatively low costs (Abessa et al., 2012). For example, São Paulo is the most populated state in Brazil and its coastal zone is covered by a number of different sewage outfalls with total maximum flows of $>13.8 \mathrm{~m}^{3} \mathrm{~s}^{-1}$ (CETESB. CETESB. Companhia Ambiental do Estado de São Paulo, n.d.). Prior to submarine discharges, treatment of sewage usually only consists of screening, settling of solids and chlorination (CETESB. CETESB. Companhia Ambiental do Estado de São Paulo, n.d.; Abessa et al., 2005). As a result, the incomplete removal of contaminants can be observed in sewage from these SSOs, released in the coastal areas that can also receive contaminants from wastewater inputs via coastal rivers, diffuse sources and urban runoff. The coastal sites attended by SSOs have high ecological and economic relevance through activities including tourism, fishing and boating and the population of these regions can increase substantially during summer (December-February), and the volume of effluents discharged may surpass the and treatment capacity of sewage treatment facilities (CETESB. Companhia Ambiental do Estado de São Paulo. São Paulo Environmental Agency, 2013).

This study assessed a number of EDCs and PhACs in sediments sampled close to SSOs from São Paulo State Coast. Due to the trace levels (ng mL $\mathrm{m}^{-1} / \mathrm{ng} \mathrm{g}^{-1}$ or less) of EDCs and PhACs, the detection and quantification of microcontaminants in complex environmental matrices such as sediments can represent a challenge (Sosa-Ferreira et al., 2013; Arditsoglou and Voutsa, 2011). The strong interaction between analytes and environmental matrices can increase detection and quantification limits, without significant inputs of, often laborious, preanalytical clean extraction and clean-up (Nuñez et al., 2015). Both the physicochemical properties of contaminants, as well matrix complexity, are important to determine the ideal extraction and analysis conditions (Halm-Lemeille and Gomez, 2016). The quick, easy, cheap, effective, rugged and safe (QuEChERS) represents a simplified extraction and clean-up technique involving the determination of these compounds that has been widely used. The procedure involves a single extraction followed by a salting out partitioning step using different salts $(\mathrm{NaCl}$, $\mathrm{MgSO}_{4}$ ) and the increasing recovery of analytes in the organic phase followed by a dispersive SPE (d-SPE) (Cerqueira et al., 2008; GonzaloLumbreras et al., 2014). In this sense, a multiresidue method using GC-MS/MS and LC-MS/MS were optimized and applied to the extracted samples. An ecological risk assessment of the concentrations found was performed at the risk characterization level in order to estimate the impact of these compounds on non-target organisms in coastal systems.

\section{Experimental}

\subsection{Reagents}

Standards: triclosan (TCS), methyltriclosan (MeTCS), bisphenol A (BPA), 17- $\alpha$ ethynylestradiol (EE2), 17- $\beta$ estradiol (E2), estrone (E1), estriol (E3), 4-nonylphenol (4NP), 4-t-octylphenol (4-t-OP), triclosan d3 (TCSd3), bisphenol A d16 (BPAd16), phenyl nonylphenol ${ }^{13} \mathrm{C}\left(\mathrm{PnP}^{13} \mathrm{C}\right)$, $17-\beta$ estradiol ${ }^{13} \mathrm{C}_{2}\left(\mathrm{E} 2{ }^{13} \mathrm{C}_{2}\right)$ and estrone ${ }^{13} \mathrm{C}_{2}\left(\mathrm{E} 1{ }^{13} \mathrm{C}_{2}\right)$ and all pharmaceuticals (SM-4) were purchased from Sigma Aldrich (NSW, Australia), $17 \alpha$-ethynylestradiol ${ }^{13} \mathrm{C}_{2}\left(\mathrm{EE} 2{ }^{13} \mathrm{C}_{2}\right)$ was purchased from ScyVac Pty Ltd. (NSW, Australia). Acetonitrile, methanol and acetic acid were purchased from Thermo Fisher Scientific (Vic, Australia). PSA and C18 dispersive salts, Florisil, Pyridine, BSTFA + TCMS were purchased from Sigma Aldrich (NSW, Australia).

Stock solutions were prepared in methanol from commercial standards in a concentration of $1 \mu \mathrm{g} \mathrm{mL}{ }^{-1}$. The labeled standards: $\mathrm{TCSd}_{3}$, $\mathrm{BPAd}_{16}, \mathrm{PnP}^{13} \mathrm{C}, \mathrm{E} 2{ }^{13} \mathrm{C}_{2}, \mathrm{E} 1{ }^{13} \mathrm{C}_{2}$ and $\mathrm{EE} 2{ }^{13} \mathrm{C}_{2}$ were prepared at a concentration of $0.3 \mu \mathrm{g} \mathrm{mL}{ }^{-1}$ where $0.4 \mathrm{~mL}$ was added to each sample $12 \mathrm{~h}$ before extraction procedure (final concentration of $50 \mathrm{ng} \mathrm{g}^{-1}$ ). All solutions were stored at $-20^{\circ} \mathrm{C}$ in the dark and used for a period of 6 months. Florisil was activated for $24 \mathrm{~h}$ at $80^{\circ} \mathrm{C}$ before use.

\subsection{Sample collection}

For method optimization, sediments were sampled in Santos Bay, São Paulo State Coast, Brazil $\left(24^{\circ} 00.436 \mathrm{~S} 46^{\circ} 21.341 \mathrm{~W}\right)$ in triplicate, in December 2012. Sediment was sampled using a Van Veen grab sampler and stored in aluminium containers. Redox potential $(\mathrm{mV})$ was measured in the top $2 \mathrm{~cm}$ of each sediment sample and bottom water was also sampled for measurements of $\mathrm{pH}$ and salinity (PSU). In the laboratory, composite sediments were homogenized, freeze dried and stored at $-4{ }^{\circ} \mathrm{C}$ until analysis. The sediment characteristics were as follows: total carbon (3.9\%); organic carbon (3.4\%); total nitrogen (0.35\%); $\mathrm{CaCO}_{3}$ (4.5\%); clay (32.7\%); silt (29.6\%); sand (16.7\%); total fines (62.3\%). Sediments for CECs assessment from seven submarine outfalls from São Paulo State Coast (Fig. 1) were sampled on December 17-18, 2012 (before the tourist season peak) and February 14-15, 2013 (following carnival festival and the end of tourist season peak). Sites included Tupi (T), Forte (F), Guarujá (G), Santos (S), Araçá (A), Ilhabela (I) and Cigarras (C), which underwent the same preparation procedures in the laboratory. Information about sampling points environmental conditions and sediments properties are described on SM-1.

\subsection{Method optimization}

For QuEChERS method using d-SPE, sediment ( $1 \mathrm{~g}$ ) was extracted with acetonitrile and $0.1 \%$ acetic acid $(10 \mathrm{~mL})$ and Milli-Q water $(5 \mathrm{~mL})$ and vortexed in $40 \mathrm{~mL}$ glass vials. Then $\mathrm{MgSO}_{4}(1 \mathrm{~g})$ and $\mathrm{NaCl}(1 \mathrm{~g})$ was added to the vials which were vortexed again and centrifuged for $10 \mathrm{~min}$ at $1500 \mathrm{rpm}$. After extraction, $5 \mathrm{~mL}$ of supernatant was removed and placed into vials containing the d-SPE salts (C18 and PSA), vortexed and centrifuged following the previous conditions. From this extract, $4 \mathrm{~mL}$ was placed in another test tube, concentrated to $1 \mathrm{~mL}$ under a $\mathrm{N}_{2}$ stream and transferred to a chromatography vial. On the day of GC-MS/MS analysis, extracts were dried and resuspended with $1 \mathrm{~mL}$ of the derivatization (silylation) reagents, pyridine and BSTFA + TMCS (4:1) added to a thermal block at $60^{\circ} \mathrm{C}$ for $30 \mathrm{~min}$ and immediately injected for analysis. For pharmaceuticals, collected QuEChERS were injected directly into an LC-MS/MS.

\subsection{Apparatus}

\subsection{1. $G C-M S / M S$}

The system used for EDCs determination was a gas chromatograph (Agilent Technologies SA) tandem mass spectrometry (GC-MS/MS) triple quadrupole (QqQ) operating in MRM (multiple reaction monitoring) mode. The column used was HP-5MS Agilent 19091S-433 $\left(30 \mathrm{~m} \times 250 \mu \mathrm{m} \times 0.24 \mu \mathrm{m}\right.$ film thickness) using $\mathrm{He}\left(1 \mathrm{~mL} \mathrm{~min}^{-1}\right)$ as carrier gas. The injector temperature was set at $250{ }^{\circ} \mathrm{C}$ in splitless mode with an injection volume of $1 \mu \mathrm{L}$. The oven program used was: $130^{\circ} \mathrm{C}$ (0.5 min) then $40^{\circ} \mathrm{C} \mathrm{min}{ }^{-1}$ until $240{ }^{\circ} \mathrm{C}$ and $5^{\circ} \mathrm{C} \mathrm{min}{ }^{-1}$ until $280^{\circ} \mathrm{C}$ $(3.75 \mathrm{~min})$ with a total running time of $15 \mathrm{~min}$. Chromatographic properties of each analyte investigated are present in SM-2 and the typical chromatogram as well as quantifier ion in SM-3. For quantification, chromatograms were processed using Agilent MassHunter Worskstation Software Version B0502, 2008.

\subsection{2. $L C-M S / M S$}

For PhACs, extracts were determined by LC-MS/MS (Thermo 


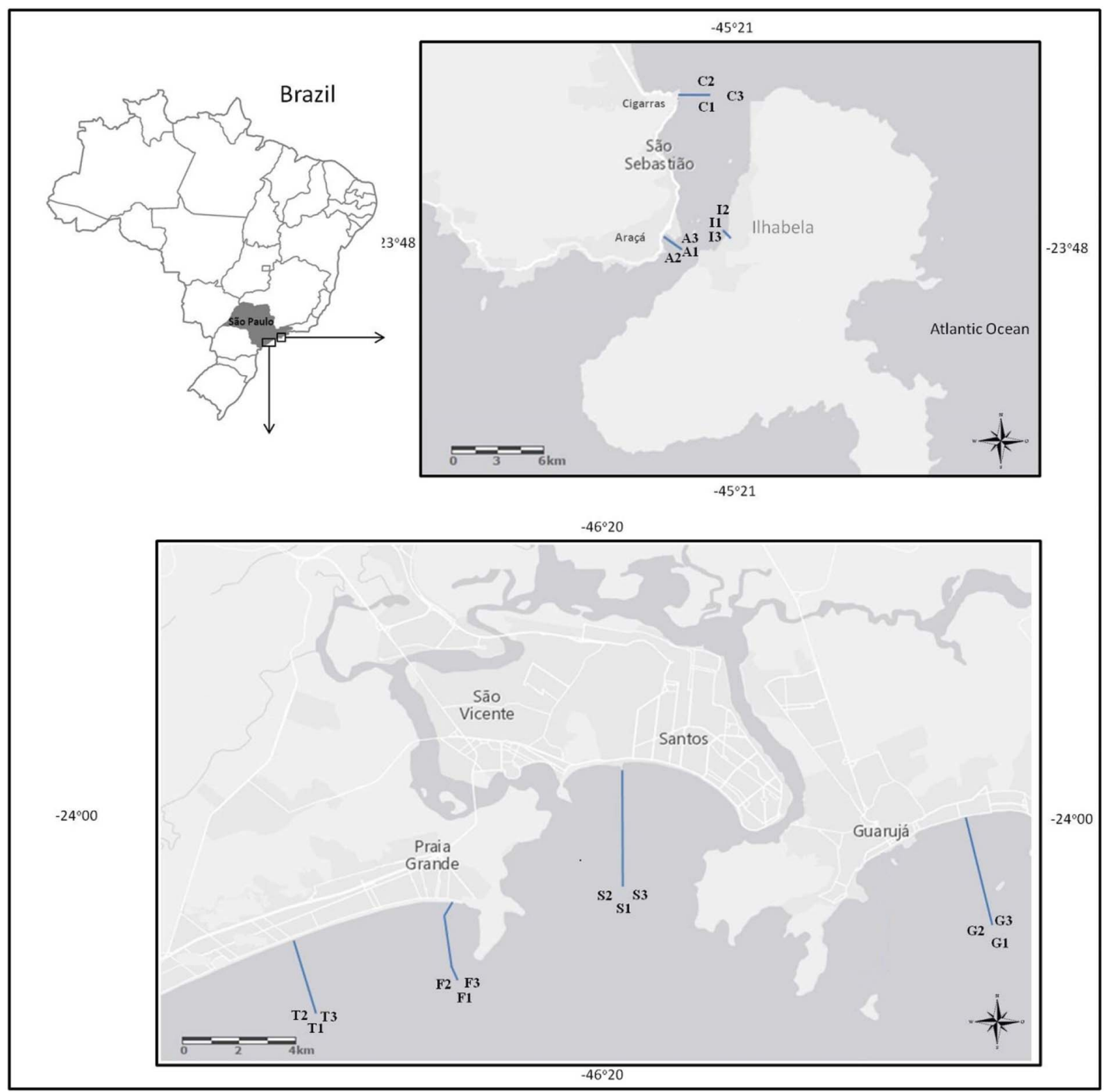

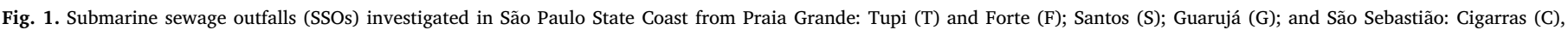
Ilhabela (I) and Araçá (A).

Finnigan TSQ quantum Discovery Max) using electrospray ionization (ESI) in positive mode. System parameters includes Atlantis T3 column T3 (Waters), $3 \mu \mathrm{m}(2.1 \times 100 \mathrm{~mm}) \mathrm{C} 18$ cover surface $\left(\mu \mathrm{mol} / \mathrm{m}^{2}\right) 1.84$, pressure of 144 bar; $10 \mu \mathrm{L}$ injection volume; mobile phase composed by ammonium formate $10 \mathrm{mM}$ in $0.1 \%$ formic acid in Milli-Q water (A) and methanol (B), for 30 min running time. Chromatographic properties of PhACs (as well as benzalkonium chloride) are included in SM-4.

\subsection{Quality control}

In all validation analysis, labeled standards $(0.4 \mathrm{~mL}$ for final concentration of $50 \mathrm{ng} \mathrm{g}^{-1}$ ) were added to check the recovery of tested method: $\mathrm{TCSd}_{3}, \mathrm{BPAd}_{16}, \mathrm{EE} 2{ }^{13} \mathrm{C}_{2}, \mathrm{E} 2{ }^{13} \mathrm{C}_{2}, \mathrm{E} 1{ }^{13} \mathrm{C}_{2}$ and $\mathrm{PnP}{ }^{13} \mathrm{C}$. Quality control of GC was also checked using QC standards between samples, calibration curves $(n=7)$ in the beginning and end of each sample list, as well as blank (solvent) and sample blank (tested sediment). Linearity was checked for each compound in the range of calibration curve ( 1 to $\left.200 \mathrm{ng} \mathrm{mL}{ }^{-1}\right)$ where points outside linearity limits $(\mathrm{k}=3)$ were removed from linear regression equation used for quantification. Matrix effect (ME) was performed based on difference (\%) between angular coefficient of curve prepared in solvent and prepared in matrix sample, where results $>10 \%$ of suppression/enhancement represent interference of this matrix on analyte chromatographic response. Instrument detection limit (IDL) was estimated based on 3 times the lowest concentration over signal noise ratio. For the final method, Method Detection Limit (MDL) were calculated as 3.3 times standard deviation of matrix blank samples over the slope of calibration curve prepared on matrix while Method Quantification Limit (MQL) were based on the lower spiked concentration with a recovery above 70\% and RSD below $20 \%$. For EDCs, precision and accuracy were determined in triplicate by spiked samples at three levels: Level 1: $10 \mathrm{ng} \mathrm{g}^{-1}$ for $4 \mathrm{NP} ; 25 \mathrm{ng} \mathrm{g}^{-1}$ for 4-t-OP and $5 \mathrm{ng} \mathrm{g}^{-1}$ for all other compounds; Level 2: $50 \mathrm{ng} \mathrm{g}^{-1}$; Level 3: $100 \mathrm{ng} \mathrm{g}^{-1}$. For PhACs the spiked levels were: 5,25 and $100 \mathrm{ng} \mathrm{g}^{-1}$ for SOT, TRM, MTX, MTP, VFL_O, DPH, DTZ, VRM, ABV, PRD, PRO, CRT and GBL; 10, 50 and $100 \mathrm{ng} \mathrm{g}^{-1}$ for ATE, BZM, CYP, BZD, PRP, CBZ, FLX and AZT; and 25, 50 and $100 \mathrm{ng} \mathrm{g}^{-1}$ for OLA, SFM and VFL. 


\subsection{Risk assessment}

The environmental risk assessment (ERA) was based on a deterministic approach by using the risk quotient (RQ) method to estimate the potential toxicity related to the concentration levels of exposure. Ecotoxicological data of the target compounds in waterborne exposures were obtained from previous studies (Gao et al., 2014; Xu et al., 2015) and also from the ECOTOX database of USEPA (USEPA. United States Environmental Protection Agency, n.d.). This information is detailed at Supplementary information (SM-5) and were used to calculate the predicted no effect concentrations (PNECs). An assessment factor ( $f$ ) of 10,000 for 4t-OP, TCS and BPA and 100 for EE2 were applied, following the different trophic levels and ecotoxicity data for marine environment according to Technical Guidance Document (TGD) from the European Commission (EC. European Commission, 2003). The risk of toxicity was considered to be related to the aqueous phase exposure due to the general absence of ecotoxicological data for benthic organisms. For this purpose, the measured environmental concentration (MEC) was calculated using the partitioning method for interstitial water $\left(\mathrm{C}_{\mathrm{w}}\right)$ and based on concentration in sediments $\left(\mathrm{C}_{\mathrm{s}}\right)$, organic carbon partitioning coefficient $\left(\mathrm{K}_{\mathrm{oc}}\right)$ and organic carbon fraction $\left(\mathrm{f}_{\mathrm{oc}}\right)$ (EC. European Commission, 2003; OECD, 1992) following the equation:

$\mathrm{C}_{\mathrm{w}}=\frac{\mathrm{C}_{\mathrm{s}}}{\mathrm{K}_{\mathrm{OC}} x f_{\mathrm{OC}}}$

The RQ consisted in the calculated ratio between the MEC and the respective PNEC values, where:

$\mathrm{RQ}=\frac{\mathrm{MEC}}{\mathrm{PNEC}}$

Values of $\mathrm{RQ} \geq 1$ were considered to indicate a potential risk existed while results $<1$ indicated no adverse effects to biota were likely. This was further refined according to Blair et al. (2013) and the evaluation was refined to low risk when $\mathrm{RQ}<0.1$ ), medium risk for RQ between 0.1 and $1(0.1<\mathrm{RQ}<1)$ and high risk when RQ values are above 1 (RQ $\geq 1$ ).

\subsection{Data analysis}

A $21 \times 7$ matrix was constructed for the multivariate data treatment. The samplers were assigned in rows as cases, while 4NP, TCS, E1, sum of EDCs and sediment parameters (redox, $\mathrm{pH}$ and \% of fines) were defined as variables and placed in the columns. The matrix columns were auto-scaled and then PCA was performed by GNU Octave 4.0.3.

\section{Results and discussion}

\subsection{Method optimization}

The QuEChERS method performance using PSA/C18 indicated a good performance for all compounds (SM-6 and SM-7). For the purification step, an extra clean-up step was evaluated using Florisil since previous studies had observed the reduction of signal suppression, analyte losses and interferences (Gonzalo-Lumbreras et al., 2014; Salvia et al., 2012). However, in the present work, the use of Florisil increased the chromatographic response for most compounds leading to higher relative standard deviations (RSD). Therefore, method validation was carried without Florisil clean-up step.

Surrogate recoveries were satisfactory (92-120\%) with RSD $<20 \%$. Linearity was checked using seven calibration levels prepared in matrix, using sediment blank samples, in a range of $1-200 \mathrm{ng} \mathrm{g}^{-1}$ for EDCs and between 0.25 and $200 \mathrm{ng} \mathrm{g}^{-1}$ for pharmaceuticals. Calibration curves matrix matched present good correlation factors $(>0.99)$ for all compounds except for benzalkonium chloride. Method detection limits (MDLs) and method quantification limits (MQLs) were satisfactory for sediment analysis in accordance with significant environmental levels.
The matrix effect checked by matrix matching calibration curves ranged from $28 \%$ (TCS) to $68 \%$ (EE2), demonstrating matrix interference for GC-MS/MS analysis and visible enhancement of chromatographic signal (SM-6). To account for this interference on quantification, matrix matched calibration (MMC) was used for quantification of all compounds in this study.

Recovery of spiked samples ranged between 60 and 130\% with a bias of -40 to $24 \%$ (SM-6). Intraday precision of the method of the three spiked levels was $<20 \%$. Labeled surrogates $\left(50 \mathrm{ng} \mathrm{g}^{-1}\right)$ responses were determined by GC-MS/MS software to correct analyte quantification. The lower recoveries for EDCs were observed for E3 (60-74\%). Similar results were reported in Pojana et al. (2007) using SPE C18 in freshwater sediments and obtaining recoveries between 65 and $94 \%$ for estrogens. Estrogens have a high potential to be associated with sediments, especially EE2 (Gunatilake et al., 2014). For PhACs, matrix effects were observed for all compounds (SM-6). MDLs and MQLs for PhACs, as well as the recovery levels, were similar to those described in literature (Celano et al., 2014; Jelic et al., 2009).

\subsection{Sediment samples}

The validated QuEChERS method was applied to sampled sediments from seven submarine outfalls in São Paulo State Coast. Seven of the nine selected EDCs were detected in sediments (Table 1). Surrogate recovery was between 70 and $130 \%$ and was used to correct analyte losses for quantification.

PhACs were not detected in any sediment sample although the presence of benzalkonium chloride in all samples indicates the discharge of sewage in the sediment collection areas. PhACs have been detected worldwide, including in regions as remote as Antarctica (Emnet et al., 2015) due to human activity in area. However, few studies have been developed in marine environment (Halm-Lemeille and Gomez, 2016). In Brazil, a previous study including 7 of the 26 PhACs were investigated in sewage sludge and also not detected (Celano et al., 2014). However, Beretta et al. (2014) have detected highly mobile compounds such as atenolol $\left(14.3 \mathrm{ng} \mathrm{g}^{-1}\right)$ and carbamazepine (4.81 $\mathrm{ng}^{-1}$ ) at Baía de Todos os Santos, due to hospital and urban discharges. A recent work, developed by Pereira et al. (2016) in Santos submarine outfall have detected 5 PhACs (acetaminophen, ibuprofen, losartan, valsartan and diclofenac) in seawater samples in concentrations ranging from 10.8 to $2094 \mathrm{ng} \mathrm{L}^{-1}$. The only PhACs in common with our study was atenolol and concentrations in seawater were below detection limit as observed in sediments in this study. Thus, the absence of PhACs occurrence in our study may be related to their physicochemical properties, where these compounds preferentially remaining within the water column due to respective water solubility and relatively low $\log \mathrm{K}_{\mathrm{ow}}$ values of the selected PhACs (Petrie et al., 2015; Thuy and Loan, 2014). It is also possible that preference of PhACs used within this demographic were such that the release of the targeted PhACs was not sufficient to allow detection.

Nonylphenol (4NP) was detected in all samples from December, ranging from 13.3 to $72.5 \mathrm{ng} \mathrm{g}^{-1}$ and from < MQL to $68.5 \mathrm{ng} \mathrm{g}^{-1}$ in the February samples. NP consists of a mixture of different isomers of which 4NP is considered to be the most common (Gatidou et al., 2010). However, NP peaks were integrated together, and the expressed results refer to NP and not only the 4NP isomer. The higher amount of NP refers to Cigarras SSO located on northern coast (São Sebastião), which has a lower flux capacity. Although sediments collected around this SSO's diffusers are composed mostly of sand (64\%), the fine particles of these sediments are carried by effluent flux and contaminants associated can be transported to another area surrounding the submarine outfall (Teodoro et al., 2009). Samples collected in February in the same SSO presented similar concentrations and the increased percentage of fines (SM-1) indicated that grain size distribution can affect the sorption of these contaminants. Similar levels of NP in marine sediments were detected recently on San Francisco Bay $\left(34.7 \mathrm{ng} \mathrm{g}^{-1}\right)$ 
Table 1

Results of CECs analysis in marine sediments collected at the vicinities of submarine sewage outfalls from the São Paulo State Coast. Results expressed in ng $g^{-1} \pm$ RSD\%. $(n=3$ ).

\begin{tabular}{|c|c|c|c|c|c|c|c|c|c|}
\hline & $4 \mathrm{NP}$ & TCS & MeTCS & $4 \mathrm{tOP}$ & BPA & $\mathrm{E} 1$ & E2 & E3 & EE2 \\
\hline \multicolumn{10}{|l|}{ December/2012 } \\
\hline Tupi (T1) & $17.7 \pm 3.8$ & $<1^{\#}$ & $\mathrm{a}$ & $<25^{\#}$ & $<5^{\#}$ & $\mathrm{a}$ & $\mathrm{a}$ & $\mathrm{a}$ & $\mathrm{a}$ \\
\hline Forte (F1) & $54.4 \pm 3.2$ & $\mathrm{a}$ & $\mathrm{a}$ & $49.2 \pm 17$ & $5.2 \pm 1.2$ & $\mathrm{a}$ & $\mathrm{a}$ & $\mathrm{a}$ & $\mathrm{a}$ \\
\hline Guarujá (G3) & $13.3 \pm 13$ & $<1^{\#}$ & $\mathrm{a}$ & $<25^{\#}$ & $7.1 \pm 0.3$ & $\mathrm{a}$ & $\mathrm{a}$ & $\mathrm{a}$ & $\mathrm{a}$ \\
\hline Santos (S2) & $33.6 \pm 1.6$ & $3.3 \pm 7$ & $<1^{\#}$ & $<25^{\#}$ & $5.1 \pm 0.3$ & $\mathrm{a}$ & $\mathrm{a}$ & $\mathrm{a}$ & $\mathrm{a}$ \\
\hline Araçá (A1) & $14.9 \pm 8.6$ & $<1^{\#}$ & $\mathrm{a}$ & $\mathrm{a}$ & $<5^{\#}$ & $\mathrm{a}$ & $\mathrm{a}$ & $\mathrm{a}$ & $\mathrm{a}$ \\
\hline Ilhabela (I1) & $58.5 \pm 1.7$ & $\mathrm{a}$ & $\mathrm{a}$ & $\mathrm{a}$ & $\mathrm{a}$ & $\mathrm{a}$ & $\mathrm{a}$ & $\mathrm{a}$ & $\mathrm{a}$ \\
\hline Cigarras (C1) & $72.5 \pm 9.4$ & $\mathrm{a}$ & $\mathrm{a}$ & $\mathrm{a}$ & $<5^{\#}$ & $\mathrm{a}$ & $\mathrm{a}$ & $\mathrm{a}$ & $\mathrm{a}$ \\
\hline Frequency & $100 \%$ & $14.3 \%$ & $0 \%$ & $14.3 \%$ & $42.8 \%$ & $0 \%$ & $0 \%$ & $0 \%$ & $0 \%$ \\
\hline \multicolumn{10}{|l|}{ February/2013 } \\
\hline Tupi 1 (T1)* & $67.7 \pm 20$ & $1 \pm 4.7$ & $\mathrm{a}$ & $<25^{\#}$ & $<5^{\#}$ & $5.7 \pm 6.2$ & $\mathrm{a}$ & $\mathrm{a}$ & $15.9 \pm 1.6$ \\
\hline Tupi 2 (T2) & $68.5 \pm 20$ & $<1^{\#}$ & $\mathrm{a}$ & $<25^{\#}$ & $<5^{\#}$ & $<5^{\#}$ & $\mathrm{a}$ & $\mathrm{a}$ & $<5^{\#}$ \\
\hline Tupi 3 (T3) & $45 \pm 16$ & $<1^{\#}$ & $\mathrm{a}$ & $<25^{\#}$ & $<5^{\#}$ & $<5^{\#}$ & $\mathrm{a}$ & $\mathrm{a}$ & $<5^{\#}$ \\
\hline Forte $1(\mathrm{~F} 1)^{*}$ & $51 \pm 9$ & $5.03 \pm 8$ & $\mathrm{a}$ & $<25^{\#}$ & $<5^{\#}$ & $7.6 \pm 0.8$ & $\mathrm{a}$ & $\mathrm{a}$ & $<5^{\#}$ \\
\hline Forte 2 (F2) & $50 \pm 21$ & $<1^{\#}$ & $\mathrm{a}$ & $\mathrm{a}$ & $\mathrm{a}$ & $<5^{\#}$ & $\mathrm{a}$ & $\mathrm{a}$ & $<5^{\#}$ \\
\hline Forte 3 (F3) & $35 \pm 34$ & $<1^{\#}$ & $\mathrm{a}$ & $\mathrm{a}$ & $<5^{\#}$ & $<5^{\#}$ & $\mathrm{a}$ & $\mathrm{a}$ & $<5^{\#}$ \\
\hline Guarujá 1 (G1) & $61 \pm 23$ & $1.52 \pm 6.5$ & $\mathrm{a}$ & $<25^{\#}$ & $<5^{\#}$ & $<5^{\#}$ & $\mathrm{a}$ & $\mathrm{a}$ & $<5^{\#}$ \\
\hline Guarujá 2 (G2) & $51 \pm 5.5$ & $1.23 \pm 4.1$ & $\mathrm{a}$ & $\mathrm{a}$ & $<5^{\#}$ & $5.8 \pm 1.3$ & $\mathrm{a}$ & $\mathrm{a}$ & $<5^{\#}$ \\
\hline Guarujá 3 (G3)* & $53 \pm 14$ & $5.29 \pm 5.7$ & $\mathrm{a}$ & $<25^{\#}$ & $<5^{\#}$ & $6.4 \pm 5.7$ & $\mathrm{a}$ & $\mathrm{a}$ & $<5^{\#}$ \\
\hline Santos 1 (S1) & $<10$ & $1.05 \pm 7.4$ & $\mathrm{a}$ & a & $\mathrm{a}$ & $<5^{\#}$ & $\mathrm{a}$ & $\mathrm{a}$ & $6.1 \pm 4.4$ \\
\hline Santos 2 (S2)* & $<10$ & $2.19 \pm 3.2$ & $\mathrm{a}$ & $\mathrm{a}$ & $\mathrm{a}$ & $6.3 \pm 2.6$ & $\mathrm{a}$ & $\mathrm{a}$ & $<5^{\#}$ \\
\hline Santos 3 (S3) & $20 \pm 11$ & $2.29 \pm 5.9$ & $4.82 \pm 13.3$ & $\mathrm{a}$ & $\mathrm{a}$ & $5.9 \pm 1.2$ & $\mathrm{a}$ & $\mathrm{a}$ & $<5^{\#}$ \\
\hline Araçá 1 (A1)* & $16.5 \pm 3.7$ & $4.45 \pm 17.5$ & $2.15 \pm 25$ & $\mathrm{a}$ & $<5^{\#}$ & $5.8 \pm 1.3$ & $\mathrm{a}$ & $\mathrm{a}$ & $<5^{\#}$ \\
\hline Araçá 2 (A2) & $10.4 \pm 8.3$ & $1.08 \pm 11.6$ & $<1^{\#}$ & $\mathrm{a}$ & $\mathrm{a}$ & $5.6 \pm 4.5$ & $\mathrm{a}$ & $\mathrm{a}$ & $<5^{\#}$ \\
\hline Araçá 3 (A3) & $13.7 \pm 5.8$ & $<1^{\#}$ & $<1^{\#}$ & $<25^{\#}$ & $<5^{\#}$ & $5.7 \pm 1.4$ & $\mathrm{a}$ & $\mathrm{a}$ & $<5^{\#}$ \\
\hline Ilhabela 1 (I1)* & $<10^{\#}$ & $\mathrm{a}$ & $\mathrm{a}$ & $<25^{\#}$ & $<5^{\#}$ & $<5^{\#}$ & $\mathrm{a}$ & $\mathrm{a}$ & $<5^{\#}$ \\
\hline Ilhabela 2 (I2) & $11.4 \pm 10$ & $\mathrm{a}$ & $\mathrm{a}$ & $\mathrm{a}$ & $\mathrm{a}$ & $5.8 \pm 2$ & $\mathrm{a}$ & $\mathrm{a}$ & $\mathrm{a}$ \\
\hline Ilhabela 3 (I3) & $12.8 \pm 3.3$ & $\mathrm{a}$ & $\mathrm{a}$ & $\mathrm{a}$ & $<5^{\#}$ & $5.9 \pm 1.7$ & $\mathrm{a}$ & $\mathrm{a}$ & $<5^{\#}$ \\
\hline Cigarras $1(\mathrm{C} 1)^{*}$ & $13.5 \pm 16.4$ & $\mathrm{a}$ & $\mathrm{a}$ & $\mathrm{a}$ & $<5^{\#}$ & $5.9 \pm 4.9$ & $\mathrm{a}$ & $\mathrm{a}$ & $<5^{\#}$ \\
\hline Cigarras 2 (C2) & $15 \pm 14$ & $<1^{\#}$ & $\mathrm{a}$ & $\mathrm{a}$ & $\mathrm{a}$ & $<5^{\#}$ & $\mathrm{a}$ & $\mathrm{a}$ & $<5^{\#}$ \\
\hline Cigarras 3 (C3) & $12.3 \pm 9.5$ & $\mathrm{a}$ & $\mathrm{a}$ & $\mathrm{a}$ & $\mathrm{a}$ & $<5^{\#}$ & $\mathrm{a}$ & $\mathrm{a}$ & $\mathrm{a}$ \\
\hline Frequency & $100 \%$ & $47.6 \%$ & $9.5 \%$ & $0 \%$ & $0 \%$ & $57.1 \%$ & $0 \%$ & $0 \%$ & $9.5 \%$ \\
\hline
\end{tabular}

${ }^{\mathrm{a} B e l o w ~ m e t h o d ~ d e t e c t i o n ~ l e v e l ~(M D L) ; ~ \# b e l o w ~ M Q L ~ b u t ~ a b o v e ~ M D L ; ~ * s u b m a r i n e ~ o u t f a l l ~ m a i n ~ e x i t . ~}$

(Klosterhaus et al., 2013). In Greek coastal sediments, the occurrence of NP was reported as more abundant $\left(266 \mathrm{ng} \mathrm{g}^{-1}\right)$ among other phenolic compounds including BPA, steroid estrogens and OP) (Arditsoglou and Voutsa, 2011). During the February campaign, higher levels of NP were detected in Tupi and Guarujá SSOs, regions characterized by intensive human occupation during carnival festivities. The frequency of this compound can be associated not only with inputs from human activities, being partially removed during sewage treatment (40-70\%), but also due to the persistence of NPs (Luo et al., 2014). However, as described above in São Paulo State SSOs there is likely to be minimal contaminant removal during the treatment process.

Octylphenol (4-t-OP) was detected only during the December campaign, at Forte SSO $\left(49.2 \pm 17 \mathrm{ng} \mathrm{g}^{-1}\right)$. The broad application of alkylphenols polyethoxylates (APEOs) in industrial, agricultural and urban uses leads to formation of degradation products such as NPs or OPs in aquatic environment (Dong et al., 2015). These compounds have a half-life higher than 60 days (Shang et al., 1999) and due to the high affinity with organic matter (Dong et al., 2015; Soares et al., 2008) and their persistence (Sosa-Ferreira et al., 2013) are expected to be found in sediments. Concentrations of NP in marine sediments collected in a marine protected area in Hong Kong were higher in rainy season due to an increase in temperature and degradation of nonylphenol ethoxylates (NPEO) combined with the effect of superficial runoff (Xu et al., 2015). Similarly, Dong et al. (2015) detected higher 4NP and 4-t-OP in rainy seasons due to runoff of material accumulated during the dry season, changes in partitioning equilibrium through rain dilution and higher AP sorption caused by lower salinity. All these factors can explain the occurrence of higher APs amounts in samples collected in December at the beginning of rainy season, in comparison with those collected in February where the dilution factor can be taken into account.

Triclosan was detected in December samples in Santos, the biggest capacity SSO $\left(7267 \mathrm{~L} \mathrm{~s}^{-1}\right)$, with a concentration of $3.3 \mathrm{ngg}^{-1}$. In
February, TCS was also detected at the same site (S2) at a lower concentration $\left(1.05 \mathrm{ng} \mathrm{g}^{-1}\right)$. The occurrence of TCS was also observed in all samples from Santos (S1 and S3), Guarujá (G1, G2 and G3), Tupi (T1), Forte (F1) and Araçá (A1 and A2). For TCS, higher concentrations were detected in sites located in close proximity to the SSO diffusers, probably due to the strong association of TCS with organic carbon in sediments (Katz et al., 2013). In sediments from deep zones, TCS has been detected close to a sewage outfall in Barker Inlet, South Australia in concentrations ranging from 5 to $27 \mathrm{ng} \mathrm{g}^{-1}$ (Fernandes et al., 2011). In comparison with data from other coastal regions, the concentrations in this study are relatively low (Cantwell et al., 2010; Emnet et al., 2015; Bu et al., 2013). The half-life of triclosan in sediments is about 540 days (Halden and Paull, 2005) and the residence time of TCS in water is short in estuarine regions due to partitioning with organic carbon (Cantwell et al., 2010).

The methylated metabolite of TCS, MeTCS, was not detected in sediment samples from December and only at Santos (S3) and Araçá (A1) located in São Sebastião during February sampling. Fernandes et al. (2011) also detected MeTCS (2-11.4 $\mathrm{ng} \mathrm{g}^{-1}$ ) in sediments from deeper zones close to SSOs in Barker Inlet, South Australia and the results suggested that TCS methylation was not from wastewater discharge but more likely to be from an in situ transformation process.

In regions of elevated population density, concentrations of TCS in sediments can lead to chronic effects on exposed organisms (Cortez et al., 2012). In Brazil, the occurrence of TCS was reported in rivers from São Paulo State (Montagner et al., 2014) with concentrations ranging from 2.2 to $66 \mathrm{ng} \mathrm{L}^{-1}$. These concentrations, as well as in this study, are relatively low and may be due to consumption/usage habits, as well as increased solar irradiance and temperatures in tropical regions, favouring more rapid degradation (Montagner et al., 2014). In places where the long-term use of TCS is reported also leads to an observed increase in detection in sediments (Cantwell et al., 2010; Maruya 
et al., 2011). In Brazil, Campanha et al. (2015) has detected TCS in freshwater samples sampled close to a sewage treatment facility at concentrations ranging from $<0.8$ to $281 \mathrm{ng} \mathrm{L}^{-1}$.

Estrogens (E1, E2, E3, EE2) were not detected in any sediment sample from December 2012. However, in February 2013 concentrations of E1 ( $<$ MQL to $76 \mathrm{ng} \mathrm{g}^{-1}$ ) were detected in almost all samples and EE2 (n.d. to $15.9 \mathrm{ng} \mathrm{g}^{-1}$ ) at two sampling sites (Tupi 1 and Santos 1). EE2 enters sewage in a conjugated and inactive form but can be reactivated through the action of microorganisms in sewage treatment facilities (Colman et al., 2009). This compound is considered more estrogenic than the natural hormone E2 (Nash et al., 2004). Ferguson et al. (2013) investigated the temporal and intertidal variations of EE2 concentrations and observed higher concentrations during the low tide, in areas with high salinity and dissolved organic carbon content. The occurrence of E1 can be attributed to its stability in the environment once released from sewage treatment facilities, even after deconjugation process (Zhang et al., 2013). In reduced sediments, as observed in this study, EE2 can be easily reduced to E1 (Froehner et al., 2012). In a north-eastern Brazilian sewage treatment facility, E1 was the most abundant estrogenic compound in influent and effluent, indicating its major excretion by humans as well as its resistance to degradation (Pessoa et al., 2014). Using dispersion modelling for estrogens, Gimliani et al. (2016) had verified that E1 can be dispersed in higher amounts than those estimated for EE2 and E2 in the aqueous phase of Santos Bay. In our study, E1 was detected in sediments from the vicinities of the diffusers of 6 of the 7 SSOs that receive effluents treated to a primary level. The occurrence of steroid estrogens after the summer tourist season can also reflect the effect of differences in population demographics in coastal areas.

Bisphenol A was detected only in Forte, Guarujá and Santos in December and these outfalls are the most important, in terms of capacity and population serviced. The detected concentrations are also low in comparison with other studies in marine environment ( $\mathrm{Xu}$ et al., 2015). This compound can be considered as a pseudo-persistent chemical since it is used in a range of industrial process and continuously released into the environment (Vulliet et al., 2014). BPA has a lower affinity with solids compared with other EDCs, such as alkylphenols and steroidal estrogens (Willians et al., 2007), and is more often present within the water phase.

As mentioned previously, effluents from sewage treatment facilities are considered the main source of many CECs to aquatic systems because most of them are not removed by the conventional treatments available in the most of the SWTPs (Coogan et al., 2007; Chen et al., 2015). In this sense, sewage outfalls represent a constantly releasing point source with the potential to introduce elevated levels of CECs in the environment (Bayen et al., 2013). Besides input rates, water residence times and local hydrodynamics can also affect the distribution of these microcontaminants close to the source and it is possible our results can also be influenced by diffuse sources. Additional samples should be considered for considering spatial (along the outfall plume) as well as temporal scale (during the drier winter season).

While studies involving the occurrence of EDCs have been conducted in Brazil most of the information is reported for freshwater systems (Montagner et al., 2014; Campanha et al., 2015; Sodré et al., 2010; Fiedler et al., 2007). In estuarine, coastal and marine environments the knowledge about the behaviour and distribution of these organic microcontaminants is reduced when tropical regions are taken into account. For example, in estuarine systems EDCs are more strongly associated with particulate matter, in comparison with freshwater systems, and the contaminants from effluents tend to be found in sediments after precipitation of suspended particles (Abessa et al., 2005; Lai et al., 2000). Principal components analysis (PCA) from the February sampling (Fig. 2) indicates the ordination of four main groups; (i) those influenced by redox (Tupi and Forte 1 and 2); (ii) by percentage of fines and E1 concentration (Santos 3, Araçá 1 to 3 and Cigarras 1); (iii) by concentration of TCS (Forte 1 and Guarujá 3); and (iv) $\Sigma$ CECs and 4NP concentration (Tupi 1).

The major concern about the occurrence of these contaminants is related with the synergistic effect when all detected compounds are considered as EDCs (Fig. 3). The $\Sigma$ CECs demonstrate a higher contamination in SSOs located in most populated areas as Tupi, Forte, Santos e Guarujá.

\subsection{Risk assessment}

The ecological risk assessment using the measured concentrations of CECs in sediments from SSOs was predicted by using a deterministic approach (SM-5) through the RQ, with the exception of MeTCS due to a lack of ecotoxicological data. PNEC values for acute effects were 2.37; 0.08; 726; 3402; 11,925 and $40.2 \mathrm{ng} \mathrm{g}^{-1}$ for TCS, BPA, 4t-OP, 4NP, EE2 and E1, respectively. PNEC values for chronic effects values were 355 ; 24; 35,620; 421,200; 4.77 and $627 \mathrm{ng} \mathrm{g}^{-1}$ for TCS, BPA, 4t-OP, 4NP, EE2 and E1, respectively.

Based on the MEC values, samples considered with potential of causing risk $(>1)$ in acute exposures were those collected in Santos (S2) in December, as well as Forte (F1), Guarujá (G3) and Araçá (A1) for TCS in February sampling surveys. For BPA, samples from Forte, Guarujá and Santos collected in December also had RQ $>1$. With respect to chronic exposure, EE2 detected in February samples of Tupi (T1) and Santos (S1) also presented potential risks. Octylphenol (4-tOP) presented a low risk for concentrations measured in sediment samples collected in Forte.

For NP, present in the majority of sediments, there was unlikely to be any risk associated with sediment concentrations based on acute and chronic ecotoxicity data from literature. However, if the threshold value for 4NP PNEC for sediments of $39 \mathrm{ng} \mathrm{g}^{-1}$ is considered (EC. European Commission, 2003), Forte, Ilhabela and Cigarras from December; Tupi (T1, T2 and T3), Forte (F1, F2 and F3) and Guarujá (G1, G2 and G3) from February samples could be at concentrations that may indicate a potential risk. Samples from Baixada Santista (Santos, Guarujá, Forte and Tupi) present a higher risk associated probably due to greater inputs from a higher population density. The use of native benthic species in future studies would be desirable to test the assumptions presented from the derivation of RQ values.

The medium risk $(0.1<\mathrm{RQ}<1)$ relating to acute exposure were observed for all other sediment samples containing TCS and E1. With respect to chronic toxicity, BPA may also present a medium risk. The synergistic effects of these compounds must also be considered, especially in organisms whose risk can be enhanced due to multiple routes of exposure (Petrie et al., 2015).

The ecological risk of CECs can be better considered based on the chemical properties and environmental aspects that influence an organism's exposure (Katz et al., 2013). In our study, we addressed the risk of acute and chronic toxicity considering only aqueous phase exposures and our analysis is an important screening level risk characterization for a number of EDCs in marine sediments of tropical environments. A more thorough assessment of sediment toxicity evaluation using local benthic biota as target species would therefore be desirable.

\section{Conclusions}

Sediments from seven SSOs investigated had a number of EDCs detected using an effective QuEChERS multiresidue extraction and clean-up method, combined with GC-MS/MS and LC-MS/MS analysis. No PhACs targeted in this sampling campaign were detected, although it is not clear whether this was related to their physicochemical properties and/or use patterns within the community. Nonylphenol was the most ubiquitous EDC detected in sediments collected in close proximity to SSOs. Most populated areas: Santos, Guarujá and Praia Grande (Tupi and Forte) had the greatest occurrence of EDCs, particularly from February immediately following the peak tourist summer season. The 


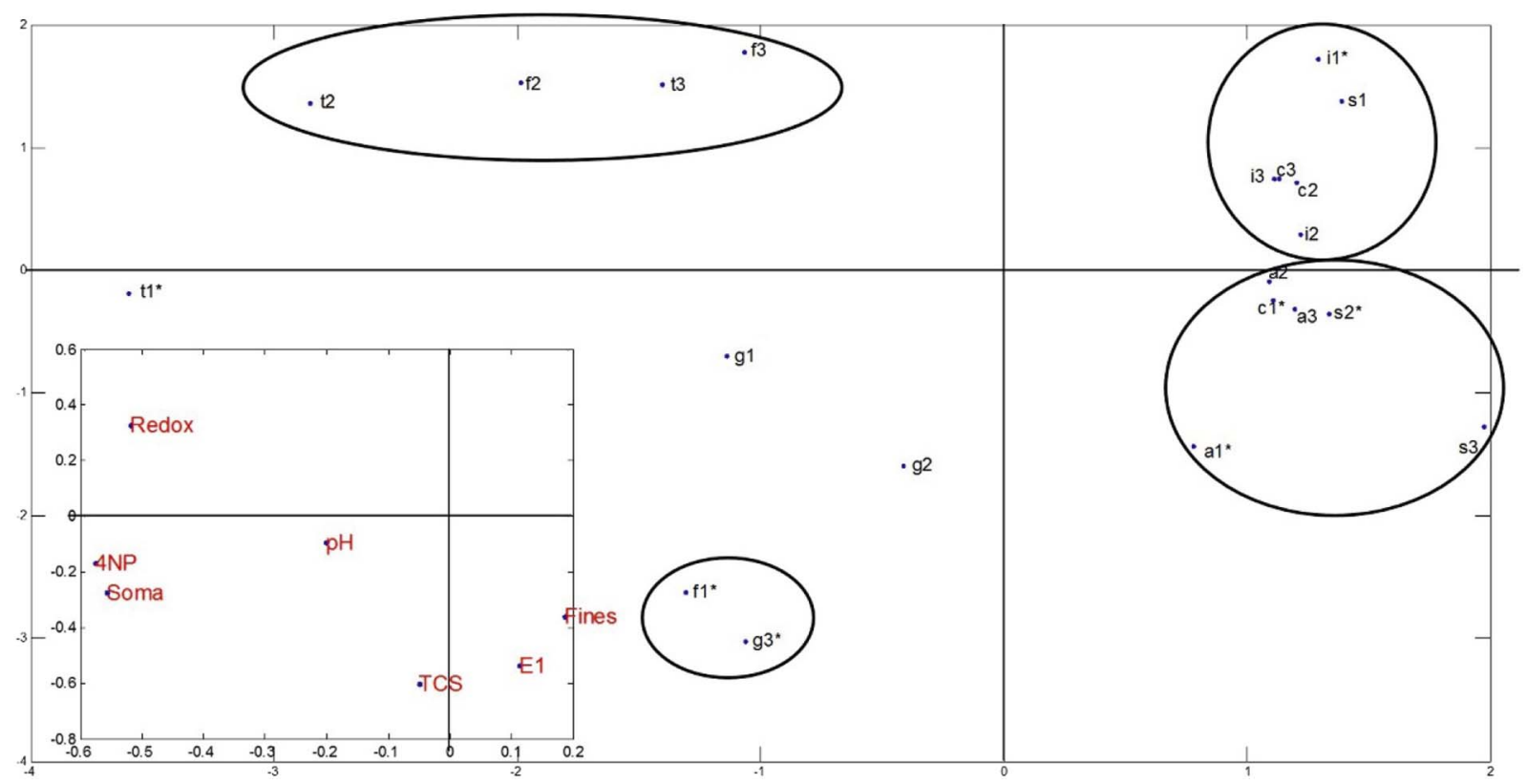

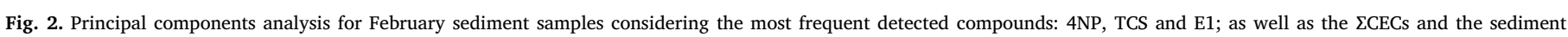
parameters: redox, $\mathrm{pH}$ and $\%$ of fines.

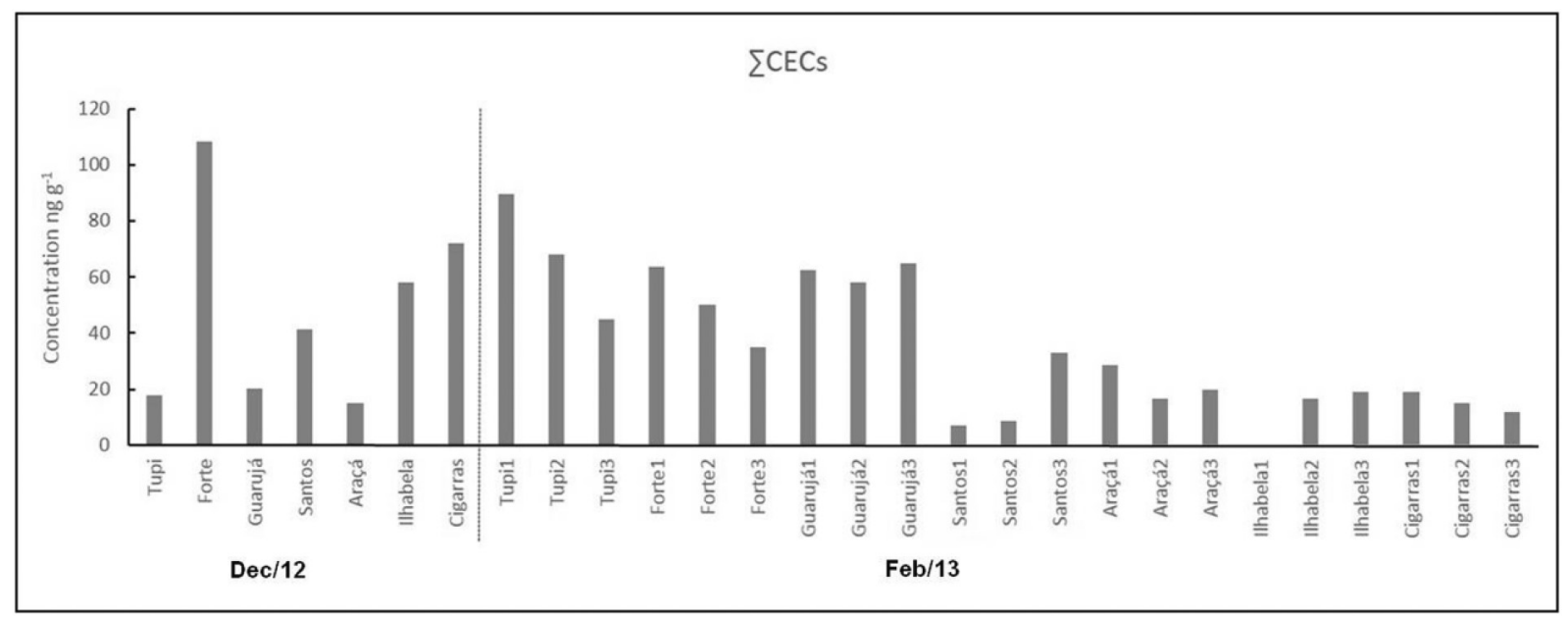

Fig. 3. $\Sigma$ CECs detected in sediments from submarine sewage outfalls.

concentrations of detected EDCs indicated the presence of some of these potential pollutants on investigated SSOs where they have the potential to cause adverse effects on organisms based on an RQ approach. Furthermore, the synergic estrogenic effect of these compounds must also be considered to more definitively define the potential risks for local marine biota.

\section{Acknowledgements}

Dr. Dayana Moscardi dos Santos and Dr. Lucas Buruaem thanks to São Paulo Research Foundation-FAPESP (grant \# 12/17898-7, 13/ 09437-2 and 13/15482-0) for the financial support. To Jun Du and Sheridan Martin from organic contaminants laboratory of CSIRO Land and Water for valuable help in chromatographic analysis and laboratory procedures and Paulo Roberto Manzani for help in sampling.

\section{Appendix A. Supplementary data}

Supplementary data to this article can be found online at https:// doi.org/10.1016/j.marpolbul.2018.02.048.

\section{References}

Abessa, D.M.S., Carr, R.S., Rachid, B.R.F., Souza, E.C.P.M., Hortelani, M.A., Sarkis, J.E., 2005. Influence of a Brazilian sewage outfall on the toxicity and contamination of adjacent sediments. Mar. Pollut. Bull. 50, 875-885.

Abessa, D.M.S., Rachid, B.R.F., Moser, G.A.O., Oliveira, A.J.F.C., 2012. Environmental effects of sewage oceanic disposal by submarine outfalls: a review. in portuguese. O Mundo da saúde, São Paulo 36 (4), 643-661.

Arditsoglou, A., Voutsa, D., 2011. Determination of phenolic and steroid endocrine disrupting compounds in environmental matrices. Environ. Sci. Pollut. Res. 15 (3), 228-236.

Arpin-Pont, L., Bueno, M.J.M., Gomez, E., Fenet, H., 2016. Occurrence of PPCPs in the marine environment: a review. Environ. Sci. Pollut. Res. 23, 4978-4991.

Bayen, S., Zhang, H., Desai, M.M., Ooi, S.K., Kelly, B.C., 2013. Occurrence and distribution of pharmaceutically active and endocrine disrupting compounds in Singapore's marine environment: influence of hydrodynamics and physical-chemical properties. Environ. Pollut. 182, 1-8.

Beretta, M., Britto, V., Tavares, T.M., Silva, S.M.T., Pletssch, A.L., 2014. Occurrence of pharmaceutical and personal care products (PPCPs) in marine sediments in the Todos os Santos Bay and the north coast of Salvador, Bahia, Brazil. J. Soils Sediments 14, 1278-1286.

Berlioz-Barbier, A., Vauchez, A., Wiest, L., Baudot, R., Vulliet, E., Cren-Olivé, C., 2014. Multi-residue analysis of emerging pollutants in sediment using QuEChERs-based extraction followed by LC-MS/MS analysis. Anal. Bional. Chem. 406, 1259-1266.

Blair, B.D., Crago, J.P., Hedman, C.J., Klaper, R.D., 2013. Pharmaceuticals and Personal 
Care Products found in the Great Lakes above concentrations of environmental concern. Chemosphere 93, 2116-2123.

Bu, Q., Wang, B., Huang, J., Deng, S., Yu, G., 2013. Pharmaceuticals and personal care products in the aquatic environment in China: a review. J. Hazard. Mater. 262, 189-211.

Campanha, M.B., Awan, A.T., Sousa, D.N.R., Grosseli, G.M., Mozeto, A.A., Fadini, P.S., 2015. A 3-year study on occurrence of emerging contaminants in a urban stream of São Paulo State of Southeast Brazil. Environ. Sci. Pollut. Res. 22, 7936-7947.

Cantwell, M.G., Wilson, B.A., Zhu, J., Wallace, G.T., King, J.W., Olsen, C.R., Burgess, R.M., Smith, J.P., 2010. Temporal trends of triclosan contamination in dated sediment cores from four urbanized estuaries: evidence of preservation and accumulation. Chemosphere 78, 347-352.

Celano, R., Piccinelli, A.L., Campone, L., Rastrelli, L., 2014. Ultra-preconcentration and determination of selected pharmaceutical and personal care products in different water matrices by solid-phase extraction combined with dispersive liquid-liquid microextraction prior to ultra high pressure liquid chromatography tandem mass spectrometry analysis. J. Chromatogr. A 1355, 26-35.

Cerqueira, M.B.R., Caldas, S.S., Primel, E.G., 2008. New sorbent in the dispersive solid phase extraction step of quick, easy, cheap, effective, rugged, and safe for the extraction of organic contaminants in drinking water treatment sludge. J. Chromatogr. A $1336,10-22$.

Cerqueira, M.B.R., Guilherme, J.R., Caldas, S.S., Martins, M.L., Zanella, R., Primel, E.G., 2014. Evaluation of the QuEChERs method for the extraction of pharmaceuticals and personal care products from drinking water treatment sludge with determination by UPLC-ESI-MS/MS. Chemosphere 107, 74-82.

\section{CETESB. CETESB. Companhia Ambiental do Estado de São Paulo São Paulo}

Environmental Agency Emissários submarinos (in portuguese). Available at: http:// www.cetesb.sp.gov.br/agua/praia Accessed in 16.06.2016.

CETESB. Companhia Ambiental do Estado de São Paulo. São Paulo Environmental Agency, 2013. Qualidade das praias litorâneas no Estado de São Paulo. Série Relatórios. (in portuguese). (215p).

Chau, W.C., Wu, J.L., Cai, Z., 2008. Investigation of levels and fate of triclosan in environmental waters from the analysis of gas chromatography coupled with ion trap mass spectrometry. Chemosphere 73, S13-17.

Chen, L., Wang, Z., Jing, Z., Wang, Z., Cao, S., Yu, T., 2015. Accumulation and risk of triclosan in surface sediments near the outfalls of municipal wastewater treatment plants. Bull. Environ. Contam. Toxicol. 95, 525-529.

Colman, J.R., Balswin, D., Johnson, L.L., Scholz, N.L., 2009. Effects of the synthetic estrogen, $17 \alpha$-ethinylestradiol, on aggression and courtship behavior in male zebrafish (Danio rerio). Aquat. Toxicol. 91, 346-354.

Coogan, M.A., Edziyie, R.E., La Point, T.W., Venables, B.J., 2007. Algal bioaccumulation of triclocarban, triclosan, and methyltriclosan in a North Texas wastewater treatment plant-receiving stream. Chemosphere 67, 1911-1918.

Cortez, F.S., Pereira, C.D.S., Santos, A.R., Cesar, A., Choueri, R.B., Martini, G.A., BohrerMorel, M.B., 2012. Biological effects of environmentally relevant concentrations of the pharmaceutical Triclosan in the marine mussel Perna perna (Linnaeus, 1758). Environ. Pollut. 168(, 145-150.

David, A., Fenet, H., Gomez, E., 2009. Alkylphenols in marine environments: distribution monitoring strategies and detection considerations. Mar. Pollut. Bull. 58, 953-960.

Dong, C.D., Chen, C.W., Chen, C.F., 2015. Seasonal and spatial distribution of 4-nonylphenol and 4-tert-octylphenol in the sediment of Kaohsiung Harbor, Taiwan. Chemosphere 134(, 588-597.

EC. European Commission, 2003. Technical Guidance Document on Risk Assessment. Part II. 337p. Disponível em: http://europa.eu.int, Accessed date: August 2015.

Emnet, P., Gaw, S., Northcott, G., Storey, B., Graham, L., 2015. Personal care products and steroid hormones in the Antarctic coastal environment associated with two Antarctic research stations McMurdo Station and Scott base. Environ. Res. 136, 331-342.

Ferguson, E.M., Allison, M., Allison, G., Swearer, S.E., Hassell, K.L., 2013. Fluctuations in natural and synthetic estrogen concentrations in a tidal estuary in south-eastern Australia. Water Res. 47, 1604-1615.

Fernandes, M., Shareef, A., Kookana, R., Gaylard, S., Hoare, S., Kildea, T., 2011. The distribution of triclosan and methyltriclosan in marine sediments of Barker Inlet, South Australia. J. Environ. Monit. 13, 801-806.

Fiedler, S., Foerster, M., Glaser, B., Zech, W., 2007. Alkylphenols in sediments of the Atlantic Rainforest south-west of São Paulo, Brazil. Chemosphere 66, 212-218.

Froehner, S., Machado, K.S., Stefan, E., Bleninger, T., Rosa, E.C., Martins, C.C., 2012. Occurrence of selected estrogens in mangrove sediments. Mar. Pollut. Bull. 64 75-79.

Gao, P., Li, Z., Gibson, M., Gao, H., 2014. Ecological risk assessment of nonylphenol in coastal waters of China based on species sensitivity distribution model. Chemosphere 104, 113-119.

Gatidou, G., Vassalou, E., Thomaidis, N.S., 2010. Bioconcentration of selected endocrine disrupting compounds in the Mediterranean mussel, Mytilus galloprovinciallis. Mar. Pollut. Bull. 60, 2111-2116.

Gimliani, G.T., Fontes, R.F.C., Abessa, D.M.S., 2016. Modeling the dispersion of endocrine disruptors in the Santos Estuarine System (São Paulo State, Brazil). Braz. J. Oceanogr. 64 (1), 1-8.

Gonzalo-Lumbreras, R., Sanz-Landaluze, J., Cámara, C., 2014. Analytical performance of two miniaturised extraction methods for triclosan and methyltriclosan, in fish roe and surimi samples. Food Chem. 146(, 141-148.

Gunatilake, S.R., Kwon, J.W., Mlsna, T.E., Xia, K., 2014. A novel approach to determine estrogenic hormones in swine lagoon wastewater using the QuEChERs method combined with solid phase extraction and LC-MS/MS analysis. Anal. Methods 6, 9267-9275.

Halden, R.U., Paull, D.H., 2005. Occurrence of triclocarban and triclosan in U.S. water resources. Environ. Sci. Technol. 39 (6), 1420-1426.

Halm-Lemeille, M.P., Gomez, E., 2016. Pharmaceuticals in the environment. Environ. Sci. Pollut. Res. 23, 4961-4963.

Jelic, A., Petrovic, M., Barceló, D., 2009. Multi-residue method for trace level determination of pharmaceuticals in solid samples using pressurized liquid extraction followed by liquid chromatography/quadrupole-linear ion trap mass spectrometry. Talanta 80, 363-371.

Jugan, M., Levi, Y., Blondeau, J., 2010. Endocrine disruptors and thyroid hormone physiology. Biochem. Pharmacol. 79 (7), 939-947.

Katz, D.R., Cantwell, M.G., Sullivan, J.C., Perron, M.M., Burgess, R.M., Ho, K.H., Charpentier, M.A., 2013. Factors regulating the accumulation and spatial distribution of the emerging contaminant triclosan in the sediments of an urbanized estuary: Greenwich Bay, Rhode island, USA. Sci. Total Environ. 443(, 123-133.

Klosterhaus, S.L., Grace, R., Hamilton, M.C., Yee, D., 2013. Method validation and reconnaissance of pharmaceuticals, personal care products, and alkylphenols in surface waters, sediments, and mussels in an urban estuary. Environ. Int. 54, 92-99.

Lai, K.M., Johnson, K.L., Scrimshaw, M.D., Lester, J.N., 2000. Binding of waterborne steroid estrogens to solid phases in river and estuarine systems. Environ. Sci. Technol. 34 (18), 34-41.

Langdon, K.A., St, M., Warne, J.M., Smernik, R.J., Shareef, A., Kookana, R.S., 2011. Selected personal care products and endocrine disruptors in biosolids: an Australiawide survey. Sci. Total Environ. 409, 1075-1081.

Luo, Y., Guo, W., Ngo, H.H., Nghien, L.D., Hai, F.I., Zhang, J., Liang, S., Wang, X.C., 2014 A review on the occurrence of micropollutants in the aquatic environment and their fate and removal during wastewater treatment. Sci. Total Environ. 473-474(, 619-641.

Maruya, K.A., Vidal-Dorsh, D.E., Bay, S.M., Kwon, J.W., Xia, K., Armbrust, K.L., 2011 Organic contaminants of emerging concern in sediments and flatfish collected near outfalls discharging treated municipal wastewater effluent to the Southern California Bight. Available in: http://ftp.sccwrp.org/pub/download/DOCUMENTS/ AnnualReports/2011AnnualReport/ar11In: Organic CECs in Marine Sediments and Fish, pp. 365-373 (access in 16.06.2016).

Montagner, C.C., Jardim, W.F., Von der Ohe, P.C., Umbuzeiro, G.A., 2014. Occurrence and potential risk of triclosan in freshwaters of São Paulo, Brazil-the need for regulatory actions. Environ. Sci. Pollut. Res. 21, 1850-1858.

Nash, J.P., Kime, D.E., Van der Ven, L.T.M., Wester, P.W., Brion, F., Maack, G., Stahlschmidt-Allner, P., Tyler, C.R., 2004. Long-term exposure to environmental concentrations of the pharmaceutical ethynilestradiol causes reproductive failure in fish. Environ. Health Perspect. 112, 1725-1733.

Nuñez, M., Borrull, F., Fontanals, N., Pocurull, E., 2015. Determination of pharmaceuticals in bivalves using QuEChERs extraction and liquid chromatography-tandem mass spectrometry. Anal. Bioanal. Chem. 407 (13), 3841-3849.

OECD, 1992. Report of the OECD Workshop on Effects Assessment of Chemicals in Sediment. Organisation for Economic Cooperation and Development (OECD), Paris OECD Environmental Monographs, n.60.

Pereira, C.D.S., Maranho, L., Cortez, F.S., Pusceddu, F.H., Santos, A.R., Ribeiro, D.A., Cesar, A., Guimarães, L.L., 2016. Occurrence of pharmaceuticals and cocaine in a Brazilian coastal zone. Sci. Total Environ. 548-549, 148-154.

Pessoa, G.P., de Souza, N.C., Vidal, C.B., Alves, J.A., Firmino, P.I., Nascimento, R.F., dos Santos, A.B., 2014. Occurrence and removal of estrogens in Brazilian wastewater treatment plants. Sci. Total Environ. 490(, 288-295.

Petrie, B., Barden, R., Kasprzyk-Hordern, B., 2015. A review on emerging contaminants in wastewaters and environment: current knowledge, understudied areas and recommendations for future monitoring. Water Res. 72, 3-27.

Pojana, G., Gomiero, A., Jonkers, N., Marcomini, A., 2007. Natural and synthetic endocrine disrupting compounds (EDCs) in water, sediment and biota of a coastal lagoon. Environ. Int. 33, 929-936.

Salvia, M.V., Vulliet, E., Wiest, L., Baudot, R., Cren-Olivé, C., 2012. Development of a multi-residue method using acetonitrile -based extraction followed by liquid chromatography-tandem mass spectrometry for the analysis of steroids and veterinary and human drugs at trace levels in soils. J. Chromatogr. A 1245, 122-133.

Shang, D.Y., Macdonald, R.W., Ikonomou, M.G., 1999. Persistence of nonylphenol ethoxylate surfactants and their primary degradation products in sediments from near a municipal outfall in the Strait of Georgia, British Columbia, Canada. Environ. Sci. Technol. 33, 1366-1372.

Soares, A., Guieysse, B., Jefferson, B., Cartmell, E., Lester, J.N., 2008. Nonylphenol in the environment: a critical review on occurrence, fate, toxicity and treatment in wastewaters. Environ. Int. 34, 1033-1049.

Sodré, F.F., Pescara, I.C., Montagner, C.C., Jardim, W.F., 2010. Assessing selected estrogens and xenoestrogens in Brazilian surface waters by liquid chromatography-tandem mass spectrometry. Microchem. J. 96, 92-98.

Sosa-Ferreira, Z., Mahugo-Santana, C., Santana-Rodríguez, J.J., 2013. Analytical methodologies for the determination of endocrine disrupting compounds in biological and environmental samples. Biomed. Res. Int. 1-23 ID674838.

Teodoro, A.C., Duleba, W., Lamparelli, C.C., 2009. Associações de foraminíferos e composição textural da região próxima ao emissário submarino de esgotos domésticos de cigarras, Canal de São Sebastião, SP, Brasil. in portuguese. Pesquisa em Geociências 36 (1), 79-94.

Thuy, H.T.T., Loan, T.T.C., 2014. Degradation of selected pharmaceuticals in coastal wetland water and sediments. Water Air Soil Pollut. 225, 1940.

USEPA. United States Environmental Protection Agency ECOTOX: The ECOTOXicology Knowledge Base. Available in: http://cfpub.epa.gov/ecotox, Accessed date: August 2016.

Vulliet, E., Berlioz-Barbier, A., Lafay, F., Baudot, R., Wiest, L., Vauchez, A., Lestremau, F., Botta, F., Cren-Olivé, C., 2014. A national reconnaissance for selected organic micropollutants in sediments on French territory. Environ. Sci. Pollut. Res. 21, 
11370-11379.

WHO. World Health Organization, 2012. State of the Science of Endocrine Disrupting Chemicals. 296p. Available at: www.who.int/ceh/publications/endicrine/en, Accessed date: 16 June 2016.

Willians, M., Woods, M., Kumar, A., Ying, G.G., Shareef, A., Karkkainen, M., Kookana, R., 2007. Endocrine Disrupting Chemicals in the Australian Riverine Environment: A
Pilot Study on Estrogenic Compounds. CSIRO Land and Water (105p).

Xu, E.G.B., Morton, B., Lee, J.H.W., Leung, K.M.Y., 2015. Environmental fate and ecological risks of nonylphenols and bisphenol A in the Cape D'Aguilar Marine Reserve, Hong Kong. Mar. Pollut. Bull. 91, 128-138.

Zhang, J., Yang, G.P., Li, Q., Cao, X., Liu, G., 2013. Study on the sorption behavior of estrone on marine sediments. Mar. Pollut. Bull. 76, 220-226. 